\title{
Experimental study of the effect of pre-bond contamination with de-icing fluid and ageing on the fracture toughness of composite bonded joints
}

\author{
E. Moutsompegka $^{1}$ | K.I. Tserpes ${ }^{1}$ (D) | P. Polydoropoulou ${ }^{1}$ | C. Tornow ${ }^{2}$ | M. Schlag ${ }^{2}$ | K. Brune ${ }^{2}$ | \\ B. Mayer $^{2}$ | S. Pantelakis ${ }^{1}$
}

\begin{abstract}
${ }^{1}$ Department of Mechanical Engineering and Aeronautics, Laboratory of Technology and Strength of Materials, University of Patras, Patras 26500, Greece

${ }^{2}$ Fraunhofer Institute for Manufacturing Technologies and Advanced Materials, Wiener Str 12, 28359 Bremen, Germany

\section{Correspondence}

K.I. Tserpes, Department of Mechanical Engineering and Aeronautics, Laboratory of Technology and Strength of Materials, University of Patras, Patras 26500, Greece. Email: kit2005@mech.upatras.gr

Funding information

European Commission, Grant/Award Number: 636494; European Union's Horizon 2020, Grant/Award Number: 636494
\end{abstract}

\begin{abstract}
The scope of the present work is to experimentally investigate the effect of pre-bond contamination with de-icing (DI) fluid and the combined effect of DI fluid and hygrothermal ageing on the fracture toughness of carbon fibre reinforced plastic bonded joints. These scenarios could occur in the implementation of an adhesively bonded patch repair in a composite aircraft structural part. To this end, mode I and mode II fracture toughness tests were conducted on contaminated specimens and mode II fracture toughness tests on contaminated/aged specimens. Three levels of contamination with a de-icer were considered. The hygrothermal ageing conditions applied until saturation are $70^{\circ} \mathrm{C} / 85 \%$ relative humidity. The experimental results reveal a detrimental effect of DI fluid on both mode I and mode II fracture toughness of the bonded joints. With increasing the contamination level, the mode I and mode II critical energy release rates decrease. Under mode I loading, the specimens failed mainly in light-fibre-tear mode, while under mode II loading, in adhesive failure mode. Hygrothermal ageing decreased further the mode II fracture toughness of the specimens and increased the adhesive failure mode. The present study reveals that the pre-bond DI contamination and after-bond ageing could critically degrade the strength of adhesively bonded patch repairs.
\end{abstract}

\section{KEYWORDS}

CFRP adhesive bonds, de-icing fluid, fracture toughness, hygrothermal ageing, pre-bond contamination

\section{1 | INTRODUCTION}

The use of adhesive bonding in aircraft structures is continuously increasing both for assembling structural parts and for applying composite patch repairs due to the numerous advantages it provides over conventional joining techniques ${ }^{1-7}$ such as the more uniform stress distribution in the joint, the ability to join dissimilar materials, the better fatigue properties, and the attractive strength-to-weight ratio. However, the use of adhesive bonding technology is limited to joining and patch repairing of structures that are not load critical. Amongst the reasons, which inhibit the wider application of adhesive

Nomenclature: $A$, energy to achieve the total propagated crack length; $D$, diffusion coefficient; $d$, crosshead displacement at crack propagation onset; $G$, energy release rate; $G_{I C}$, mode I critical energy release rate; $G_{I I C}$, mode II critical energy release rate; $h$, specimen thickness; $L$, span length; $M(t)$, normalized weight gain; $M_{\infty}$, water uptake at saturation; $P$, critical load to start the crack propagation; $S$, slope of the $M(t)$ curve; $t$, time; $w$, specimen width; $w_{o}$, initial weight; $w_{t}$, weight at exposure time $t ; \alpha$, crack length; $\alpha_{\text {final }}$, final crack length; $\alpha_{\text {initial }}$, initial crack length 
joints, is the sensitivity of the bondline integrity to the environmental effects ${ }^{1-3,6-9}$ bonded joints are exposed to during service. Runway de-icing (DI) fluid is one of the most commonly encountered fluids that adhesive bonded composite structures may be exposed to. Runway de-icers are essential to safe airport operations and are used to maximize the runway friction during all plane movements at airports in winter. Generally, airfield pavement DI products mainly consisting of urea or glycols have become less popular owing to their adverse environmental impacts. ${ }^{10,11}$ New pavement DI products have emerged as alternatives that often contain potassium acetate, sodium acetate, sodium formate, or potassium formate (KF) as the freezing point depressant. ${ }^{11}$ Contamination with DI fluid is possible to occur in the implementation of a composite patch repair in a damaged aircraft structural part as DI fluid could be swirled from the runway to outer parts of the aircraft.

Exposure to hygrothermal environments is a critical issue regarding the durability of adhesively bonded joints. There have been published several works relating the strength of an adhesive system to the degree of environmental ageing. In Johnson et al, ${ }^{12}$ an experimental investigation of the effect of the operating environment in terms of moisture and temperature on aluminium-adhesive-aluminium joints' performance is conducted. A significant reduction of the mode I fracture toughness is reported following the exposure to various hygrothermal service conditions. A comprehensive review of the durability of adhesive joints in the presence of water is provided in Bowditch. ${ }^{13}$ According to the review, water can affect both the physical and mechanical properties of the adhesive itself and also the nature of the adherent/adhesive interface. Water is absorbed by the organic adhesives, and although the effect of plasticization is expected to be negative, low concentrations of water may have the net effect of strengthening the joints. ${ }^{13}$ In Bowditch et al, ${ }^{14}$ a variety of examples of water diffusion to adhesive joints is presented including the exposure of glass-reinforced plastic adherents joint by acrylic adhesive to humid atmosphere $\left(70^{\circ} \mathrm{C} / 90 \%\right.$ relative humidity $[\mathrm{RH}])$. It is found that the strength of the joint weakens with time. In Hallidaya et al ${ }^{15}$ the adhesive bonded carbon fibre reinforced plastic (CFRP) specimens exhibited a significant loss of strength over the prolonged exposure period to conditions of $70^{\circ} \mathrm{C} / 100 \% \mathrm{RH}$. A reduction in the CFRP adhesive joint performance was also the result of exposure to $70^{\circ} \mathrm{C} / 80 \% \mathrm{RH}$ and $50^{\circ} \mathrm{C} / 96 \% \mathrm{RH}$ in Liljedahla et al. ${ }^{16}$ Regarding metallic structures, when aluminium or steel joints are subjected to accelerating ageing, they exhibit a significant loss of bond strength. ${ }^{17-20}$ Finally, in Pantelakis et al, ${ }^{7}$ the durability of bonded joints is defined for a variety of parameters that may influence bonding quality. It is shown that environmental ageing and pre-bond contamination of bonding surfaces might degrade significantly fracture toughness of bonded joints.
In contrast with other environmental factors, like moisture or temperature, no research has been published on either the effect of runway DI fluid on the adhesive composite bonds or the effect of the combined DI fluid contamination and hygrothermal ageing. The research published on the effect of the DI fluid on aircraft composite parts is mainly limited to field reports from airports. ${ }^{10,11,21,22}$ A growing body of field evidence from airline operators indicated that potassium acetate and KF may cause accelerated structural degradation of carbon-carbon (C/C) composite aircraft brakes as a result of the catalytic oxidation by the potassium cation, which may result in reduced brake life and introduce the possibility of brake failure. ${ }^{11}$ The low melting temperatures of potassium salts and their decomposition productsall below $327^{\circ} \mathrm{C}$-allow them to migrate easily on the carbon surface and form good interfacial contact with it, facilitating oxygen transfer. ${ }^{11}$

In the present work, the effect of pre-bond contamination with DI fluid and the combined effect of DI fluid and hygrothermal ageing on the fracture toughness of CFRP bonded joints are studied by means of mode I and mode II fracture toughness tests on contaminated specimens and mode II fracture toughness tests on contaminated/aged specimens.

\section{2 | FABRICATION AND PRE-BOND CONTAMINATION}

\section{1 | Materials}

Hexcel M21E is the material used for the preparation of the specimens. HexPly M21E/IMA, which was developed specifically for Airbus, from Hexcel's M21 third generation thermosetting epoxy resin system, has an intermediate modulus fibre, balancing superior strength and stiffness. The resin matrix was developed to ensure optimal translation of the carbon fibre properties while delivering outstanding fracture resistance. The sample plates were produced by Aernnova Composites using liquid water-based silicon-containing release agent Frekote C-600, to obtain smooth surfaces.

Regarding the structural layout, CFRP monolithic structures were manufactured according to Airbus AIPS 03-02-019 standard for CFRP ("Manufacture of monolithic parts with thermoset prepreg materials"). The adherents consisted of 8 unidirectional plies, and their layup sequence was $\left[0_{2}, \pm 45\right]_{s}$ according to AITM 1-0053 standard. ${ }^{23} \mathrm{~A}$ release film of $25 \mathrm{~mm}$ length for contaminated samples and $30 \mathrm{~mm}$ for contaminated/aged samples was inserted at one end of the sample prior to bonding to obtain an initial delamination. For the adhesive bonding, the film adhesive FM 300-2 from Cytec (0.2 mm thickness) was used, instead of a paste adhesive, to standardize the bondline thickness and increase reliability of the results. 


\section{2 | Specimens preparation}

\subsection{1 | Adherents preparation}

To prepare the clean reference samples from the delivered plates, the following steps were performed, and each step was monitored by X-ray photoelectron spectroscopy (XPS) analyses (Figure 1).

1. Pre-cleaning of the plates with isopropanol (IPA)-soaked tissues to remove part of the release agent and any other soluble contaminations, eg, fingerprints, remained from the manufacturing process. The XPS measurements performed on the "as delivered" plates on 3 different positions showed an inhomogeneous distribution of siliconcontaining release agent on the CFRP surface (Table 1). The XPS results on the cleaned plates showed that precleaning with IPA is effective in a sense that the amount of release agent on the CFRP surface can be reduced by it to a value of 0.5 to $1.4 \mathrm{at} \%$. This is an amount that can easily be removed by the subsequent grinding step.

2. Slight grinding of the surfaces to remove residual release agent that had penetrated or was incorporated into the topmost resin layers and afterwards wiping with demineralized water and IPA to remove the dust from a grinding and residual silicone. The new XPS measurements conducted showed a small amount of silicone remained on the surface (Table 1).

3. A second slight grinding step, followed by wiping off the dust with demineralized water and IPA. On these samples, XPS measurements showed a very clean surface (Table 1).

After the cleaning steps, the sample plates were wiped with methyl ethyl ketone-soaked tissues prior to contamination and adhesive bonding.

\subsection{2 | Contamination and bonding of adherents}

The de-icer used was SAFEWAY KF from CLARIANT. It was diluted with demineralized water to obtain solutions with
TABLE 1 XPS results for the CFRP sample plates at the cleaning steps

\begin{tabular}{lc} 
CFRP plates & Si, at\% \\
\hline CFRP “as delivered” sample plates & $5.3 \pm 1.3$ \\
\hline CFRP sample plates after IPA cleaning & $0.9 \pm 0.5$ \\
\hline $\begin{array}{l}\text { CFRP sample plates after IPA cleaning and slight } \\
\text { grinding }\end{array}$ & $0.3 \pm 0.2$ \\
$\begin{array}{l}\text { CFRP sample plates after IPA cleaning and 2 slight } \\
\quad \text { grinding steps with cleaning in between }\end{array}$ & $0.1 \pm 0.04$ \\
\hline
\end{tabular}

Abbreviations: CFRP, carbon fibre reinforced plastic; IPA, isopropanol; XPS, $\mathrm{X}$-ray photoelectron spectroscopy.

the following concentrations in vol\%: low level 2\% (DI-1), medium level 7\% (DI-2), and high level of contamination $10 \%$ (DI-3). It was applied on the surfaces by dip coating (aqueous solution) and then dried in the oven for 2 hours at $40^{\circ} \mathrm{C}$. Then acclimatization at room temperature was allowed for at least 24 hours. The dip coating results were controlled by XPS measurements. Since the de-icer contains KF, the potassium content on the surface is taken as a measure for the degree of de-icer contamination. The XPS results are shown in Table 2.

For the bonding of the CFRP plates, the adhesive was cured in an autoclave cycle in accordance with the material data sheet specifications. Finally, the sample plates were cut to the final specimen dimensions specified by the standards of the mechanical tests. Cutting was performed dry (diamond cutting) to prevent any contamination of the cleaned surfaces. After cutting, the surfaces were cleaned again with IPAsoaked tissues.

\section{3 | EXPERIMENTAL}

Mode I and mode II tests (DI tests) were conducted to characterize the fracture toughness in terms of the critical energy release rate $G$ and assess the effect of runway DI fluid on the CFRP bonded joints. The combined effect of pre-bond contamination with DI fluid and after-bond ageing was investigated by conducting hygrothermal ageing tests and subsequent mode II fracture toughness tests (A-DI tests).
FIGURE 1 Scheme for cleaning of asreceived CFRP plates. CFRP, carbon fibre reinforced plastic; IPA, isopropanol; MEK, methyl ethyl ketone; XPS, X-ray photoelectron spectroscopy. [Colour figure can be viewed at wileyonlinelibrary.com]

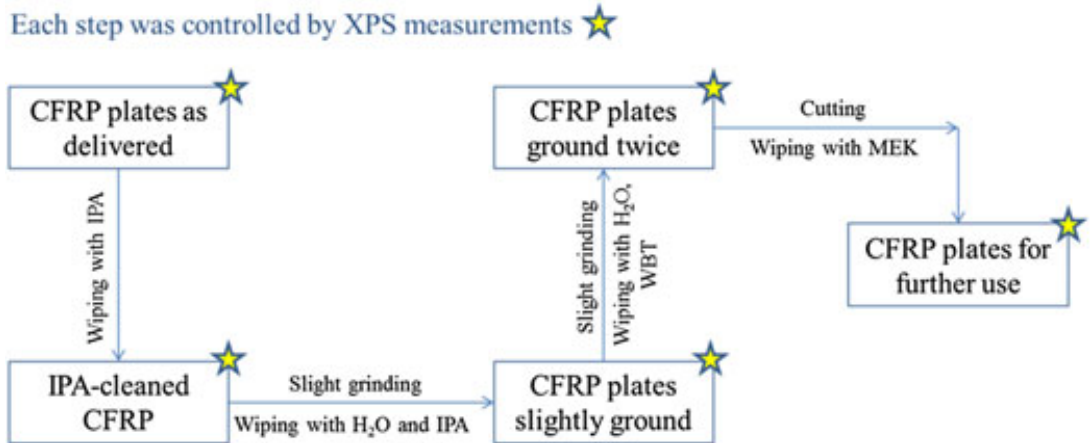


TABLE 2 Concentration of $\mathrm{K}$ in carbon fibre reinforced plastic surfaces

\begin{tabular}{lr} 
& \multicolumn{1}{c}{ K, at $\%$} \\
\hline DI-1 & $6.4 \pm 1.8$ \\
DI-2 & $10.9 \pm 2.3$ \\
DI-3 & $12.0 \pm 1.4$
\end{tabular}

\section{1 | Mode I tests}

The Airbus specification ${ }^{23}$ AITM 1-0053 defines a method to determine the mode I fracture toughness energy $G_{I C}$ of CFRP bonded joints. The double cantilever beam specimen is used, which consists of rectangular adherents bonded along their length incorporating a region of nonadhesive release film at one end for the introduction of the initial crack in the bondline (Figure 2). Load was applied in the double cantilever beam specimen via metallic piano hinges bonded to the adherents at one end. To avoid any influence of the incorporated release film, the specimen was preloaded until an initial crack length of 10 to $15 \mathrm{~mm}$ was achieved. The pre-cracked specimen was then loaded continuously by opening forces until a total propagated crack length of $100 \mathrm{~mm}$ was achieved. After that, the test was stopped, and the specimen was unloaded.

During the crack propagation, the load and crosshead displacement of the test machine were recorded continuously. A traveling microscope was used to facilitate the visual measurement of the crack length. Six specimens per scenario were tested under a tensile loading using a Tinius Olsen H5KT universal testing machine with a load cell of $5 \mathrm{kN}$ at ambient conditions $\left(25^{\circ} \mathrm{C} / 55 \% \mathrm{RH}\right)$ under displacement control. To avoid an increase in the amount of unstable crack

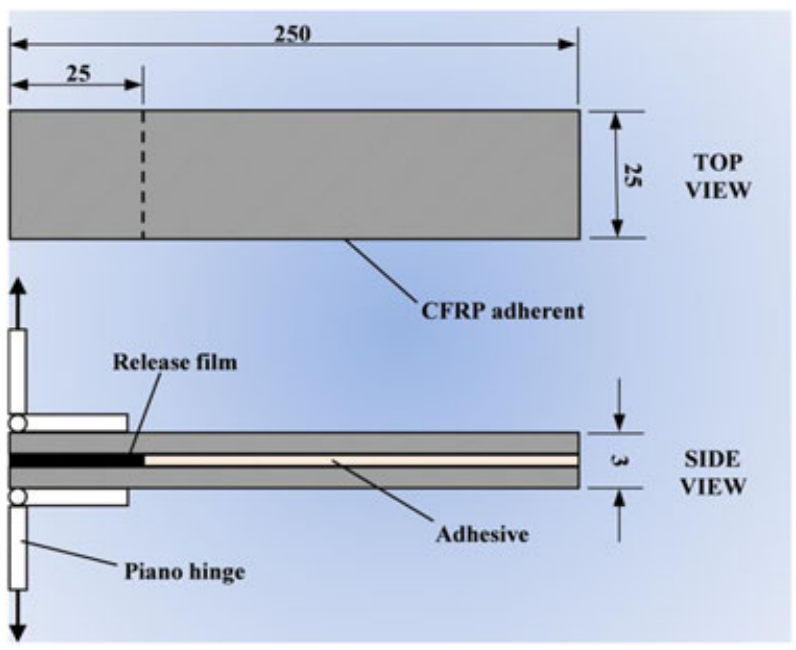

FIGURE 2 Schematic representation of the DCB specimen. DCB, double cantilever beam; CFRP, carbon fibre reinforced plastic. [Colour figure can be viewed at wileyonlinelibrary.com] propagation at high crosshead rates, ${ }^{24}$ the rate was kept constant at $5 \mathrm{~mm} / \mathrm{min}$.

The area method was applied to interpret the data recorded during the mode I tests. The crack extension is related directly to the area enclosed between the loading and unloading curves as shown in Figure 3. The mode I critical energy release rate $G_{I C}$ is derived as ${ }^{23}$

$$
G_{I C}=\frac{A}{\alpha \times w} \times 10^{6}\left(\mathrm{~J} / \mathrm{m}^{2}\right),
$$

where $A$ is the energy to achieve the total propagated crack length (J), $\alpha$ is the propagated crack length ( $\left.a=a_{\text {final }}-a_{\text {initial }}\right)$ $(\mathrm{mm})$, and $w$ is the specimen width (mm).

The most popular means of investigating delamination mechanisms in mode I tests is the examination of fracture surfaces. ${ }^{25}$ So, after the tests, the failure surfaces were examined to accurately assess the causes of bondline failure. The classification, identification, and characterization of the failure mode of the CFRP bonded joints were conducted according to ASTM D5573 standard. ${ }^{26}$ Besides the 3 basic failure modes (cohesive, adhesive, and fracture in the adherent), the ASTM D5573 standard defines a number of submodes such as fibre-tear failure in which failure occurs exclusively within the fibre-reinforced polymer matrix resulting in the appearance of fibres on both ruptured surfaces and lightfibre-tear where failure occurs within the adherent, near the surface, characterized by a thin layer of the matrix on the adhesive, with few or no fibres transferred from the substrate to the adhesive.

\section{2 | Mode II tests}

Up to now, there is no standardized test to measure the fracture toughness energy of bonded joints under pure mode II loading. Although fracture characterization of bonded joints under pure mode I has been extensively studied and

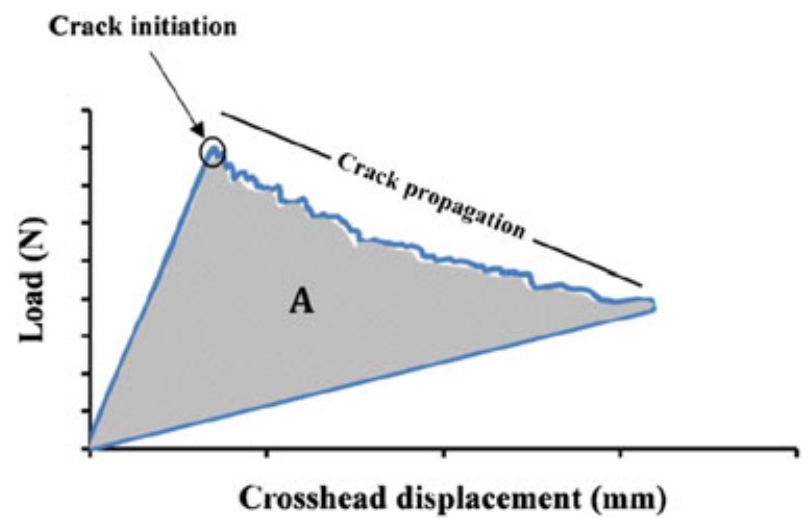

FIGURE 3 A typical load-displacement diagram of the mode I fracture toughness test. [Colour figure can be viewed at wileyonlinelibrary.com] 
standardized, mode II is still not well addressed owing to some practical aspects inherent to the most popular tests: the End Notched Flexure (ENF), the End Loaded Split, and the 4-point ENF. The End Loaded Split test involves a clamp that is a source of variability and increases the complexity of data reduction. ${ }^{3,27}$ On the other hand, the 4-point ENF test requires a complex set-up and presents some problems related to large friction effects reduction. ${ }^{3,27}$ As a consequence, the ENF specimen has emerged as the most convenient mode II fracture toughness specimen. The specimen is easy to manufacture, the test fixture is simple, and the datareduction methodology is straightforward. ${ }^{28}$

Figure 4 illustrates a schematic representation of the ENF test. A pre-cracked specimen is loaded in a 3-point bend fixture until the crack propagation onset. The pre-crack is embedded through width at the end of the specimen to accommodate the sliding deformation of the adherents that result from the flexural loading. ${ }^{28}$ To provide crack growth stability, the initial crack length was considered to be equal to $70 \%$ of $L / 2 .^{4,29}$ The load applied to the specimen and the crosshead displacement of the test machine were recorded continuously during the test.

Mode II tests were conducted according to the AITM 1-0006 standard ${ }^{30}$ at ambient conditions under a constant displacement rate of $1 \mathrm{~mm} / \mathrm{min}$ using an MTS universal testing machine with a load capacity of $100 \mathrm{kN}$. The test specimens were cut from the residual part of mode I specimens so that a pre-crack of $35 \mathrm{~mm}$ was achieved. Three specimens were tested for each condition. To facilitate the optical observation of the crack tip and the detection of the crack propagation onset, a digital microscope was used, and a thin layer of white ink was applied to the longitudinal side faces of the specimen.

To calculate $G_{I I C}$ fracture toughness energy, the following formula was used ${ }^{30}$ :

$$
G_{I I C}=\frac{9 \times P \times a^{2} \times d \times 1000}{2 \times w \times\left(1 / 4 \times L^{3}+3 \times a^{3}\right)}\left(\mathrm{J} / \mathrm{m}^{2}\right),
$$

where $d$ is the crosshead displacement at crack propagation onset (mm), $P$ is the critical load to start the crack

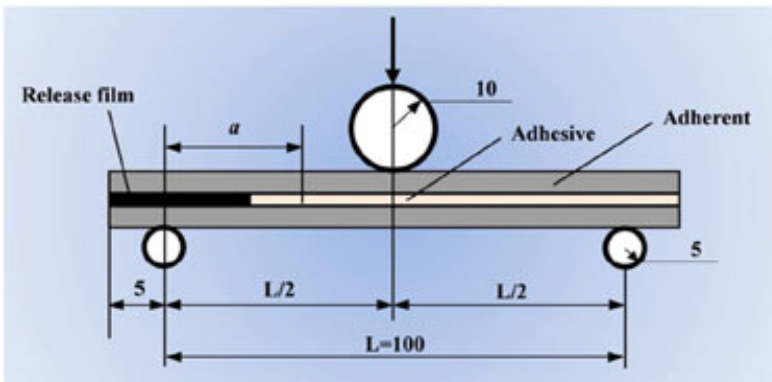

FIGURE 4 Schematic representation of the End Notched Flexure specimen. [Colour figure can be viewed at wileyonlinelibrary.com] propagation $(\mathrm{N}), a$ is the initial crack length $(\mathrm{mm}), w$ is the width of the specimen (mm), and $L$ is the span length (mm).

\section{3 | Ageing tests}

To evaluate the combined effect of DI fluid contamination and exposure to hygrothermal environment on mode II fracture toughness of CFRP bonded joints, the contaminated samples were placed into an environmental chamber in conditions of $70^{\circ} \mathrm{C} / 85 \% \mathrm{RH}$ as determined by the DIN EN 2823 standard $^{31}$ for a period of 69 to 74 days when the saturation point was reached. During the hygrothermal ageing period, the specimens' weight was measured in a weekly basis. After the hygrothermal ageing, the specimens were stored in sealed containers and tested in mode II loading conditions within 72 hours. Since the specimens for the hygrothermal ageing were tested only in mode II loading, they were not cut from any residual part of mode I specimens, thus, the specimens were placed inside the environmental chamber with an embedded pre-crack, which was created a priori through mode I tests conducted according to the AITM 1-0006 standard. ${ }^{30}$

As a measure of the absorbed humidity, the percentage normalized weight gain $M(t)$ was used.

$M(t)$ was derived from the following formula:

$$
M(t)=\left(\frac{w_{t}-w_{0}}{w_{0}}\right) \times 100,
$$

where $w_{0}$ is the initial weight $(\mathrm{g})$ and $w_{t}$ is the weight at exposure time $t(\mathrm{~g})$.

Fick's law was used to define equilibrium conditions in composite materials. ${ }^{31}$ The diffusion coefficient $D$ of water is derived from the slope of the linear part of $M(t)$ curve as

$$
D=\pi \times\left(\frac{h}{4 \times M_{\infty}}\right)^{2} \times S^{2}\left(\frac{\mathrm{mm}^{2}}{\mathrm{~s}}\right),
$$

where $M_{\infty}$ is the water uptake at saturation (\%), $h$ is the specimen thickness (mm), and $S$ is the slope of the $M(t)$ curve $\left(1 / \mathrm{s}^{0.5}\right)$.

\section{4 | RESULTS AND DISCUSSION}

\section{1 | Effect of de-icing fluid}

\subsection{1 | Mode I fracture toughness}

The experimental load-displacement curves of the mode I tests of the different DI fluid concentration levels, including the reference one, are plotted in Figure 5. It is observed that all specimens exhibited an unstable crack growth. The $G_{I C}$ values of the specimens are presented in Figure 6. The results indicate a negative effect of DI fluid as $G_{I C}$ is reduced for all 

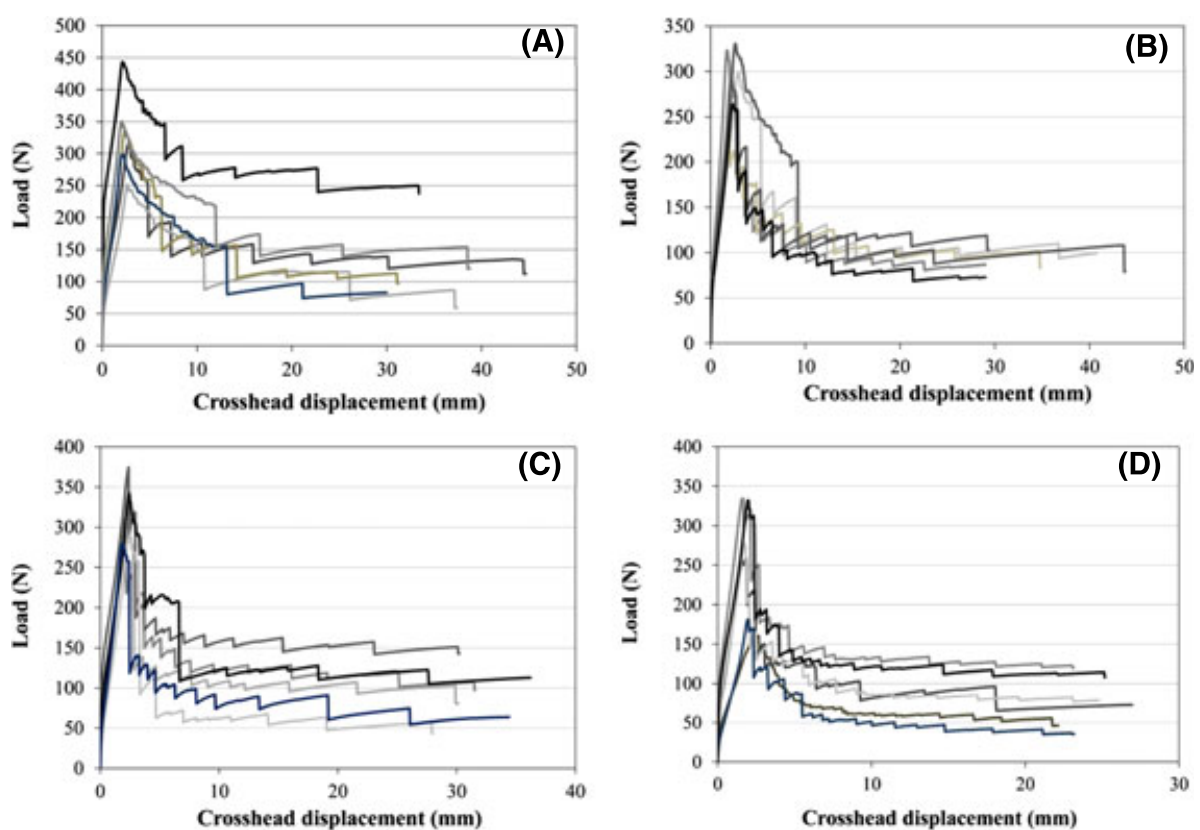

FIGURE 5 Experimental mode I load-displacement curves of A, REF B, DI-1, C, DI-2, and D, DI-3 specimens. [Colour figure can be viewed at wileyonlinelibrary.com]

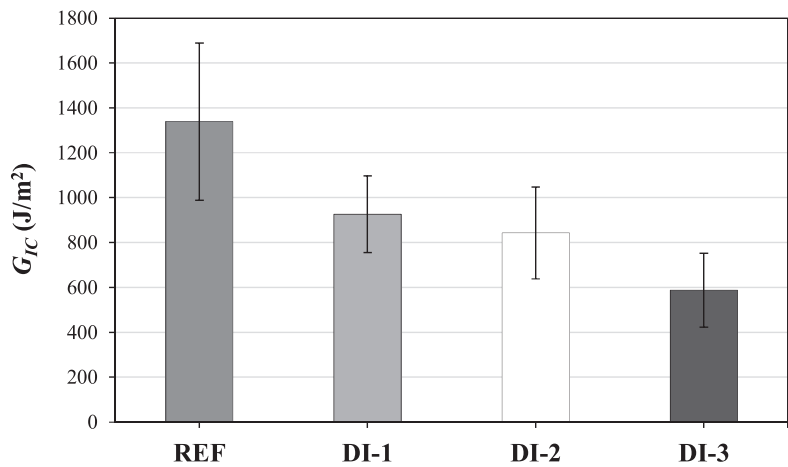

FIGURE 6 Average $G_{I C}$ values comparison

3 contamination levels. Specifically, for DI-1, the average $G_{I C}$ values show an almost 30\% reduction compared to the reference category, for DI-2, the average $G_{I C}$ is reduced further to $37 \%$, while for DI-3, the $G_{I C}$ fracture toughness of the joints degrades significantly by $56 \%$ designating the detrimental effect of DI fluid on the bond performance. The rather big scatter of $G_{I C}$ values is attributed to the complexity of adhesion mechanisms and failure mechanisms (unstable crack propagation and varying failure mode) and possibly to the non-uniformity of contamination. ${ }^{1,8}$

In Figure 7, photos of the fracture surfaces, showing the main failure modes observed in the mode I tested specimens, are illustrated, and in Figure 8, the percentages of the different failure modes are compared for the different sample sets. In the reference samples, a mixed-mode failure was observed (Figure 7A) with the dominant failure being the light-fibre-tear failure at a percentage of $50 \%$, while the cohesive failure was observed at $35 \%$ of the surface area and the adhesive failure at $15 \%$. The adhesive failure results show a large scatter, which is attributed to the fact that not all 6 specimens presented homogeneous failure; 3 samples presented
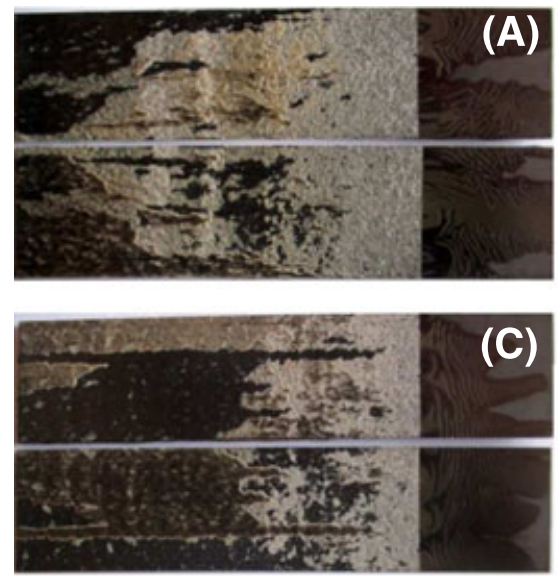
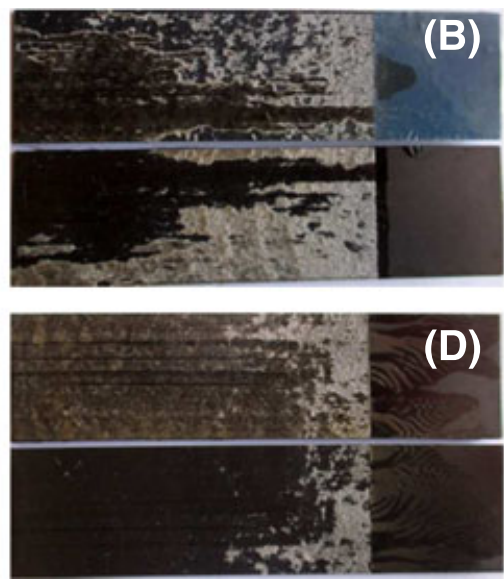

FIGURE 7 Representative fracture surfaces of the A, REF, B, DI-1, C, DI-2, and D, DI-3 specimens loaded in mode I. [Colour figure can be viewed at wileyonlinelibrary. com] 


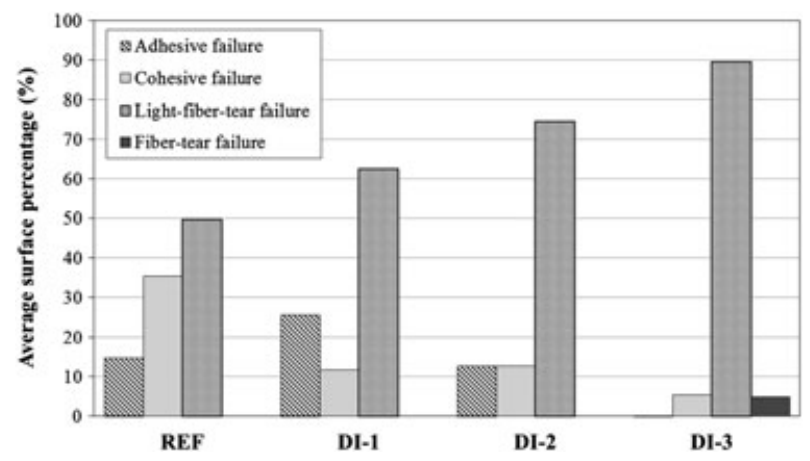

FIGURE 8 Average percentages of the failure modes presented in the mode I tested joints

adhesive failure at a percentage less than $4 \%$. The phenomenon of the non-uniform failure mode amongst samples of the same set is present in the contaminated samples sets also, revealing the complexity of crack propagation in the mode I fracture toughness tests. In the DI-1 samples (Figure 7B), the cohesive failure was reduced to $11.7 \%$, while a larger surface failed adhesively (26\%), indicating the reduction in bond strength. Light-fibre-tear failure remained the dominant failure in the DI-2 samples with a value of $63 \%$. Finally, in the DI-3 set (Figure 7D), adhesive and cohesive failure modes were reduced drastically to $0.25 \%$ and $5 \%$, respectively, while $90 \%$ of the surface area failed in light-fibre-tear mode. It is worth mentioning that one of the specimens presented fibre-tear failure. The increase of the light-fibre-tear and fibre-tear failure, as a result of the increased contamination level, indicates that the DI fluid has a deleterious impact mainly on the CFRP adherents and more specifically, on the properties of the polymeric matrix. In conclusion, with increasing the contamination level, there is an increase in the percentage of light-fibre-tear failure, which is a clear sign that the presence of DI fluid degrades the tensile strength of the matrix.

\subsection{2 | Mode II fracture toughness}

The experimental load-displacement curves of the aged and unaged ENF specimens are presented in Figure 9. The curves of the unaged specimens show an initial linear behaviour of the specimens followed by the region where matrix cracking started to accumulate at the adherents until macroscale failure of the outer layers of the adherents as a result of compression. Usually, the load increases until crack initiation, and after that, the load continuously drops. However, in the present study, the crack propagation onset was observed long before the load drop point, which hindered the precise crack propagation onset determination. This is due to the small adhesive thickness compared to the laminate thickness. ${ }^{32}$ When the crack reaches the middle point of the ENF specimen, the load starts to increase because of the development of compressive stresses near the crack tip, which obstruct further crack propagation. $^{27,29}$

The $G_{I I C}$ values of the unaged and aged specimens are presented in Figure 10. As in mode I, the impact of runway DI fluid on the mode II fracture toughness of the unaged specimens is detrimental. The increase of contamination level causes a further reduction of $G_{I I C}$. Specifically, for DI-1, a reduction of $61 \%$ is observed regarding the reference values,
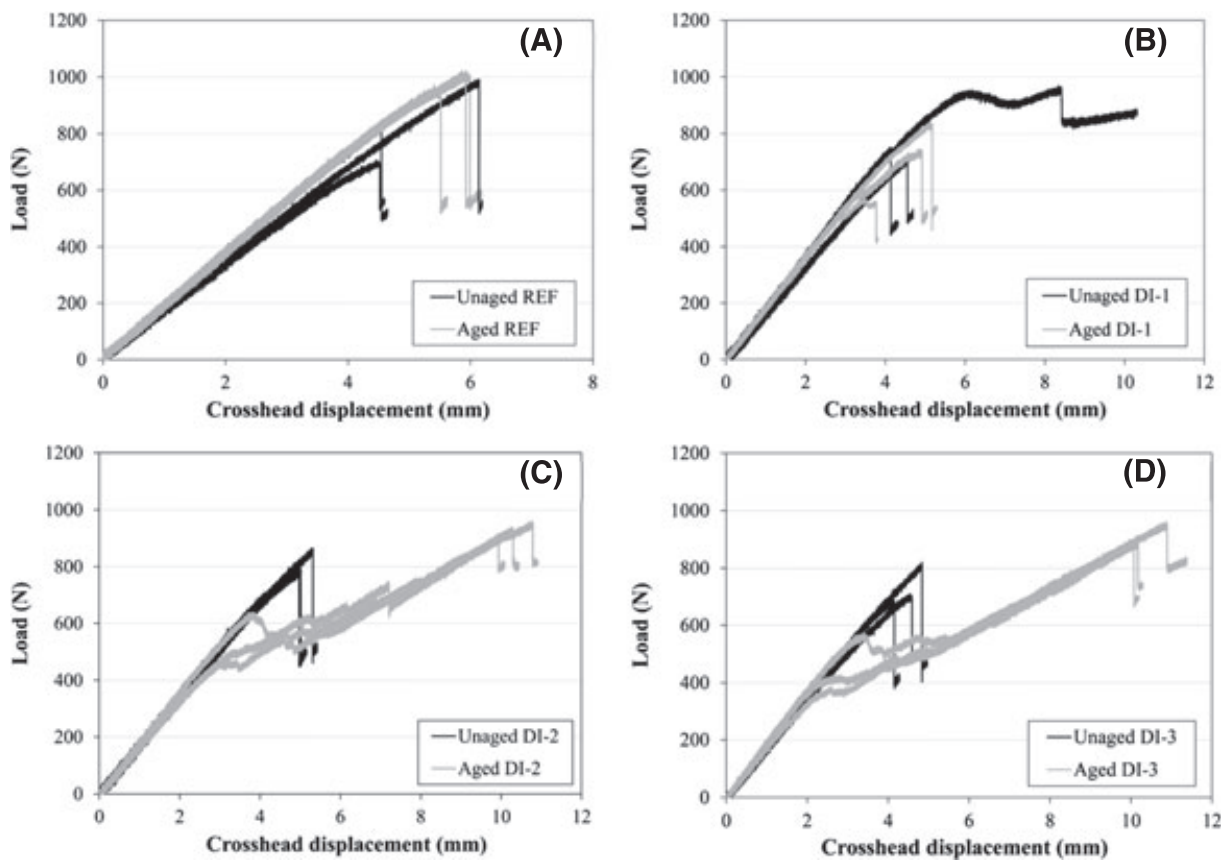

FIGURE 9 Experimental mode II load-displacement curves of A, REF, B, DI-1, C, DI-2, and D, DI-3 aged and unaged specimens 


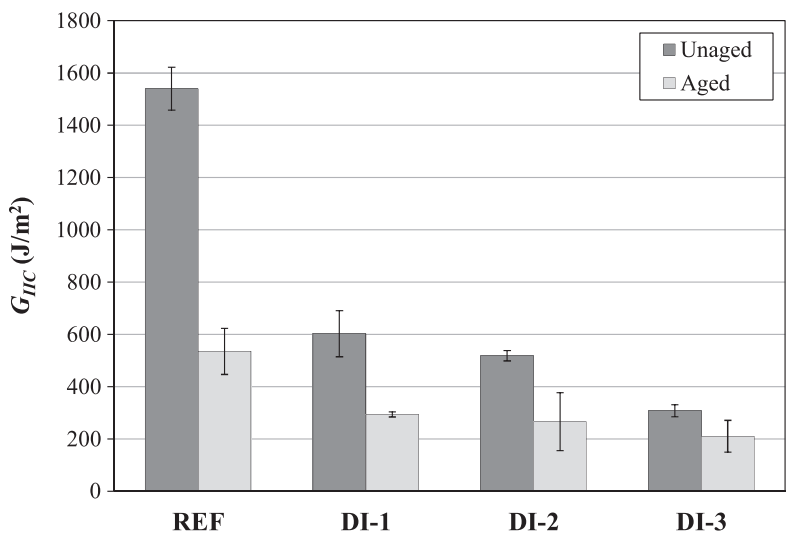

FIGURE 10 Average $G_{I I C}$ values comparison

for DI-2, the corresponding value is $66 \%$, while for DI-3, the reduction reaches $80 \%$.

Representative failure surfaces of the unaged specimens, which were tested in mode II loading, are presented in Figure 11. The percentages of the different failure modes are compared for the different sample sets in Figure 12. Mixed-mode failure was observed for all scenarios. For the reference samples (Figure 11A), the dominant failure mode was the light-fibre-tear failure at a percentage of $81 \%$ indicating that the adhesive bond is stronger than the adherent in mode II loading. For the DI-1 scenario (Figure 11B), the dominant mode remains the light-fibre-tear failure (85\%), while for the DI-2 (Figure 11C) and DI-3 (Figure 11D) scenarios, the adhesive failure increases $(56 \%$ and $78 \%$, respectively) indicating a reduction in the bondline performance due to the medium and high level of contamination. In conclusion, with increasing the contamination level, there is a transition from light-fibre-tear failure to adhesive failure, which is a clear sign of degradation of shear strength of the adherent/adhesive interface due to the presence of DI fluid. This reduction in bond strength could be attributed to the fact that the contamination of the adherents with DI fluid leads to poor adhesion between the adhesive and the adherent (formation of weak bonds). These defects are called kissing bonds

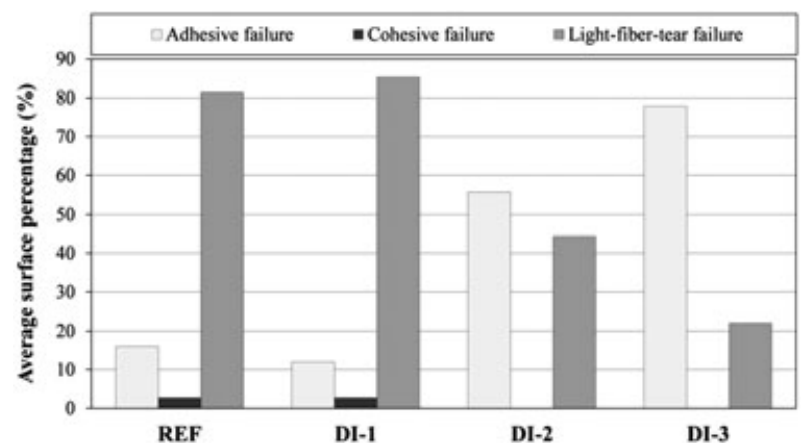

FIGURE 12 Average percentages of the failure modes presented in the mode II tested joints

or zero-volume disbonds and are extremely difficult to be detected using conventional non-destructive techniques (NDTs). There have been, however, developed extendedNDTs, ${ }^{33}$ and a more detailed investigation of the effect of DI fluid on the joints by mechanical testing and extendedNDT inspection would be interesing.

\section{2 | Combined effect of DI fluid and ageing}

\subsection{1 | Moisture absorption}

Figure 13 plots $M(t)$ regarding exposure time for the different scenarios. The diffusion parameters derived using Equations 3 and 4 for the different cases are listed in Table 3. The final water uptake is between $0.54 \%$ and $0.56 \%$, similar for all cases.

$D$ can be used to compare the diffusion rate within the material system. In DI-1 and DI-2 contamination levels, $D$ is reduced, indicating an increase in the joint's resistance to moisture absorption due to presence of DI fluid. This is probably because at low concentrations of DI fluid (DI-1 and DI-2), moisture diffusion is hindered by the thin layer of KF formed on the CFRP adherents. However, at high concentrations of DI fluid (DI-3), the KF layer is thicker and acts more like an absorbent material rather than a protection film, thus causing an increase of $D$.
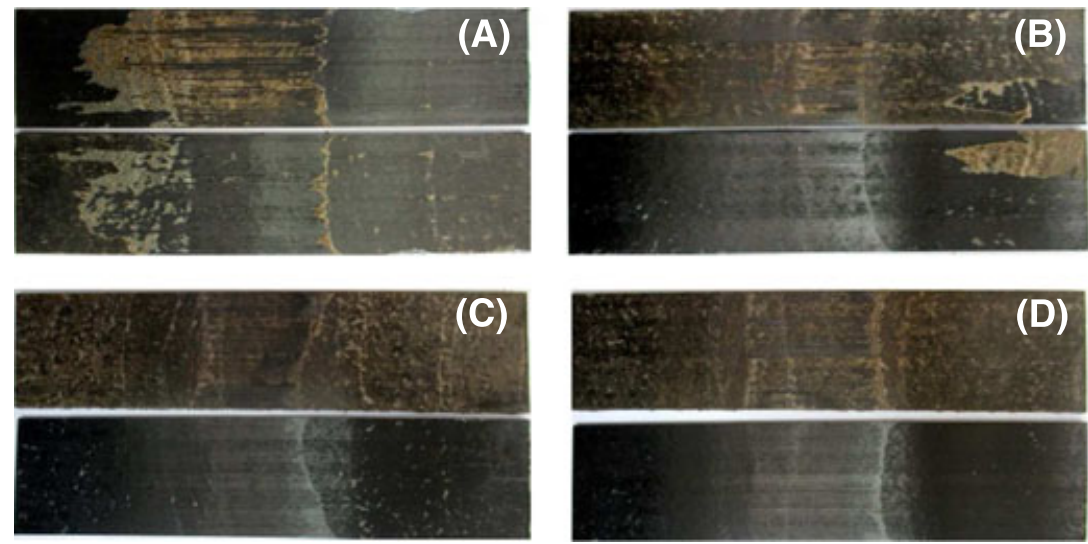

FIGURE 11 Representative fracture surfaces of the A, REF, B, DI-1, C, DI-2, and D, DI-3 specimens loaded in mode II. [Colour figure can be viewed at wileyonlinelibrary.com] 


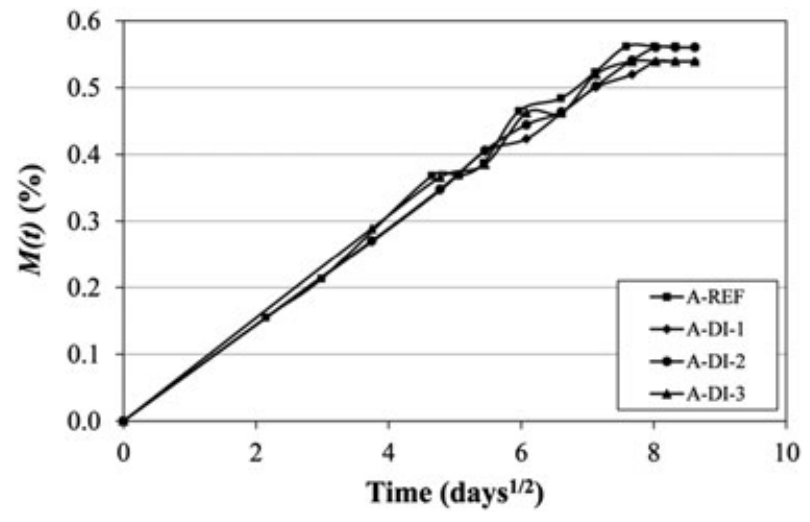

FIGURE 13 Variation of normalized weight gain $M(t)$ regarding exposure time $t$

TABLE 3 Moisture diffusion parameters

\begin{tabular}{lcc} 
& $\boldsymbol{M}_{\boldsymbol{\infty}}, \boldsymbol{\%}$ & $\boldsymbol{D}\left(\mathbf{m m}^{\mathbf{2}} / \mathbf{s}\right) \times \mathbf{1 0}^{\mathbf{- 6}}$ \\
\hline A-REF & 0.56 & 0.3922 \\
A-DI-1 & 0.54 & 0.3906 \\
A-DI-2 & 0.56 & 0.3533 \\
A-DI-3 & 0.54 & 0.4202 \\
\hline
\end{tabular}

\subsection{2 | Mode II fracture toughness}

The comparison of experimental load-displacement curves of the reference aged and unaged samples (Figure 9) shows no significant influence of hygrothermal ageing under the specified temperature and moisture conditions. On the contrary, there is slight evidence that hygrothermal ageing increased the stiffness of the joint as a result of polymer matrix plasticization. However, the $G_{I I C}$ value of the aged reference (A-REF) samples is drastically reduced by $65 \%$ compared to the unaged reference samples (Figure 10). This phenomenon is also observed in the aged/contaminated specimens and is attributed to the fact that the crack propagation onset for the $G_{I I C}$ determination is observed at the specimen side where the moisture concentration is higher. Additionally, the crack propagation occurred near the adhesive region and diffusion through the adhesive is regarded as the primary access route for moisture to enter the joint. ${ }^{13}$ Evidence for the above statements is also provided by the increased percentage of adhesive failure mode (Figures 14 and 15), which indicates a degradation of the chemical bonds across the interface due to the interaction with water. ${ }^{13}$ The comparison between the unaged and aged reference curves indicates that for the AREF samples, the degradation of the adhesive itself is the dominant factor in the adhesive failure mode, while for the A-DI samples, where the curves present an earlier fracture, it seems that the adherents have been also influenced, thus leading to adhesive failure. Specifically, the $G_{I I C}$ value of the A-DI- 1 scenario was reduced by $81 \%$ compared to the unaged reference samples, while for the A-DI-2 and A-DI-3 scenarios, the reduction was $83 \%$ and $86 \%$, respectively. Comparing the effect of DI fluid with the combined A-DI effect, it is clear that the latter is much more severe.

Representative failure surfaces of the A-DI specimens, which were tested in mode II loading, are presented in Figure 14. The percentages of the different failure modes are compared for the different sample sets in Figure 15. The A-REF samples presented a light-fibre-tear dominant failure mode in a percentage of $77.5 \%$, A-DI-1 failed mainly adhesively (65\%), while the dominant failure mode for the ADI-2 and A-DI-3 was adhesive failure (67\% and $83 \%$, respectively) revealing that the combined DI fluid contamination and hygrothermal ageing leads to a greater degradation of the bondline integrity. By comparing Figures 12 and 14, it is shown that there is the same trend regarding the effect of DI fluid, however, ageing seems to reduce the percentage of light-fibre-tear failure and enhance the percentage of adhesive failure, which is a clear sign of degradation of adhesive properties due to water uptake.

Additionally, a future study of the subject discussed in this paper could potentially include the numerical investigation the effect of pre-bond contamination with DI fluid and after-bond hygrothermal ageing in the mode I and mode II fracture toughness of the CFRP joints. Regarding the hygrothermal ageing, a usual approach is a multiple level modelling of the moisture transport through the joint and the subsequent incorporation of the hygrothermal stress-stain
FIGURE 14 Representative fracture surfaces of the aged A, A-REF, B, A-DI-1, C, A-DI-2, and D, A-DI-3 specimens loaded in mode II. [Colour figure can be viewed at wileyonlinelibrary.com]
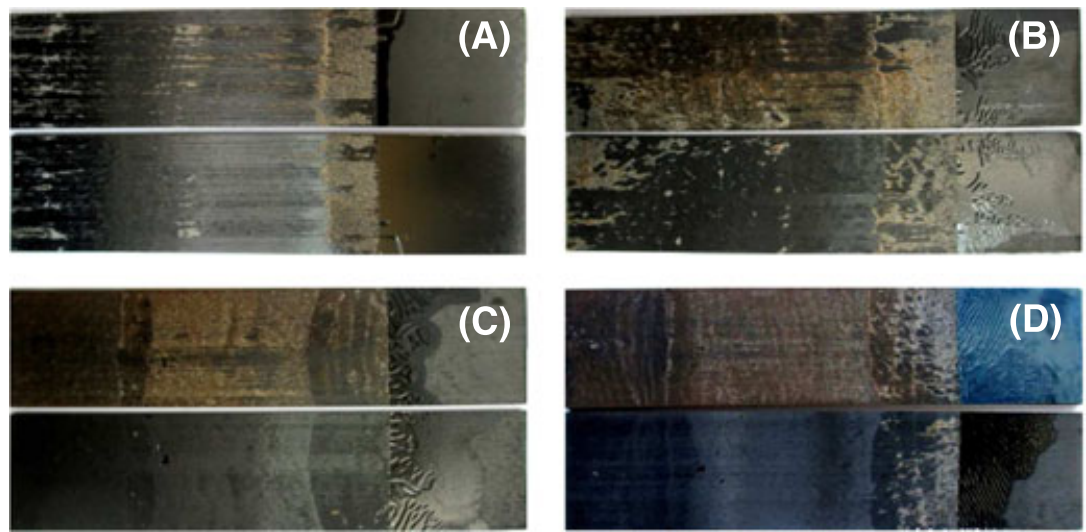


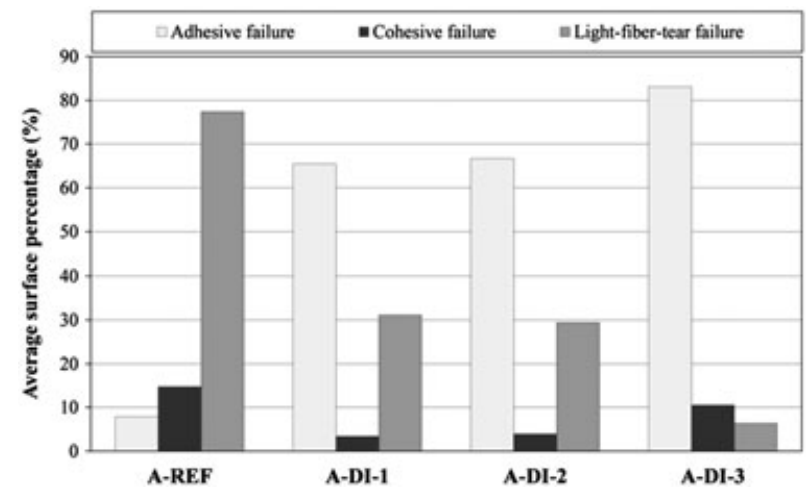

FIGURE 15 Average percentages of the failure modes presented in the mode II fractured joints after hygrothermal ageing

state. ${ }^{34}$ Process modelling of the contamination presents more challenges because of the complicated chemical phenomena involved. However, a proposed approach could be the investigation of the effect of the DI fluid on the joint through extended NDT and the incorporation of that effect in a numerical model.

\section{5 | CONCLUSIONS}

In the present work, the effect of pre-bond contamination with DI fluid and the combined effect of DI fluid and hygrothermal ageing on the fracture toughness of CFRP bonded joints were studied by means of mode I and mode II fracture toughness tests on contaminated specimens and mode II fracture toughness tests on contaminated/aged specimens. Three different levels of DI fluid contamination, namely, DI-1, DI-2, and DI-3, were used. The hygrothermal ageing conditions applied until saturation are $70^{\circ} \mathrm{C} / 85 \%$ RH. From the experimental results, the following conclusions can be drawn:

- Pre-bond contamination with DI fluid significantly degrades the mode I and mode II fracture toughness of the bonded joints. The decrease of $G_{I I C}$ is much larger than the decrease of $G_{I C}$. The higher the concentration of DI fluid, the larger the reduction in $G_{I C}$ and $G_{I I C}$ values.

- After-bond hygrothermal ageing significantly degrades the mode II fracture toughness of the composite bonded joints. The decrease is larger for the A-DI specimens, which reveals that the combined effect is more severe than the 2 separate effects.

- In most cases, a combination of adhesive failure, cohesive failure, and light-fibre-tear failure was observed. The careful examination of the percentages of the failure modes reveals that DI fluid affects mainly the properties of the polymeric matrix, while moisture affects mainly the bondline (adherent/adhesive interface and the adhesive).
- The higher the DI fluid contamination, the greater was the reduction of the $G_{I I C}$ of the contaminated/aged specimens. Regarding the failure mode of the specimens, hygrothermal ageing caused an adhesive dominant failure mode, the percentage of which was increased with the increase of the DI fluid level of contamination.

\section{ACKNOWLEDGEMENT}

The research leading to these results has received funding from the European Union's Horizon 2020 research and innovation programme under grant agreement no. 636494 (Project COMBONDT: Quality Assurance Concepts for Adhesive Bonding of Aircraft Composite Structures by Extended NDT).

\section{REFERENCES}

1. Markatos DN, Tserpes KI, Rau E, Brune K, Pantelakis S. Degradation of mode-I fracture toughness of CFRP bonded joints due to release agent and moisture pre-bond contamination. J Adhes. 2014;90(2):156-173. https://doi.org/10.1080/00218464.2013.770720

2. da Silva LFM, Öchsner A, Adams RD. Introduction to adhesive bonding technology. In: da Silva LFM, Öchsner A, Adams RD, eds. Handbook of Adhesion Technology (Vol 2). Heidelberg: Springer-Verlag Berlin; 2011:2-3.

3. de Moura MFSF. Progressive damage modelling. In: da Silva LFM, Öchsner A, eds. Modelling of Adhesively Bonded Joints. Heidelberg: Springer-Verlag Berlin; 2008:155-156, 166-171.

4. Ebnesajjad S. Adhesives Technology Handbook, 2nd Edition, William Andrew Inc, 2008.

5. Ashcroft IA, Crocombe AD. Modelling the fatigue in adhesively bonded joints. In: da Silva LFM, Öchsner A, eds. Modelling of Adhesively Bonded Joints. Heidelberg: Springer-Verlag Berlin; 2008:184

6. Charalambides MN, Hardouin R, Kinloch AJ, Matthews FL. Adhesively-bonded repairs to fibre-composite materials I. Experimental. Compos A: Appl Sci Manuf. 1998;29(11):1371-1381. https://doi. org/10.1016/S1359-835X(98)00060-8

7. Pantelakis S, Tserpes KI. Adhesive bonding of composite aircraft structures: challenges and recent developments. Sci China Phys Mech Astron. 2014;57(1):2-11. https://doi.org/10.1007/s11433013-5274-3

8. Tserpes KI, Markatos DN, Brune K, Hoffmann M, Rau E, Pantelakis S. A detailed experimental study of the effects of prebond contamination with a hydraulic fluid, thermal degradation, and poor curing on fracture toughness of composite-bonded joints. J Adhes Sci Technol. 2014;28(18):1865-1880. https://doi.org/ 10.1080/01694243.2014.925387

9. Pitt S, Jones R, Peng D. Characterization of the durability of adhesive bonds. Fatigue Fract Eng Mater Struct. 2012;35(11): 998-1006. https://doi.org/10.1111/j.1460-2695.2012.01688.x

10. Shan Yong J. Evaluation of the Environmental Impact and Alternative Technologies of Deicing/Anti-icing Operations at Airports. 
Master of Engineering in Civil and Environmental Engineering. USA: Massachusetts Institute of Technology; 2001.

11. Shi X. Impact of airport pavement deicing products on aircraft and airfield infrastructure. Airport Cooperative Research Program Synthesis 6, Transportation Research Board, Washington, D.C, USA, 2008.

12. Johnson WS, Butkus LM. Considering environmental conditions in the design of bonded structures: a fracture toughness mechanics approach. Fatigue Fract Eng Mater Struct. 1998;21:465-478. https://doi.org/10.1046/j.1460-2695.1998.00533.x

13. Bowditch MR. The durability of adhesive joints in the presence of water. Int $J$ Adhes Adhes. 1996;16(2):73-79. https://doi.org/ 10.1016/0143-7496(96)00001-2

14. Bowditch MR, Stannard KJ. Adhesive bonding of GRP. Composites. 1982;13(3):298-304. https://doi.org/10.1016/0010-4361(82) 90013-1

15. Hallidaya T, Banksa WM, Pethrickb RA. Dielectric studies of adhesively bonded CFRP/epoxy/CFRP structures-Design for ageing. Compos Sci Technol. 2000;60(2):197-207. https://doi.org/10.1016/ S0266-3538(99)00111-6

16. Liljedahla CDM, Crocombe AD, Wahaba MA, Ashcroftb IA Modelling the environmental degradation of adhesively bonded aluminium and composite joints using a CZM approach. Int $J$ Adhes Adhes. 2007;27(6):505-518. https://doi.org/10.1016/j. ijadhadh.2006.09.015

17. Joshi SB, Gray TF, Banks WM, et al. Environmental ageing of adhesively bonded joints. II. Mechanical studies. J Adhes. 1997;62(1-4): 317-335. https://doi.org/10.1080/00218469708014574

18. Ashcorft IA, Crocombe AD. Prediction of joint strength under humid conditions: damage mechanics approach. In: da Silva LFM, Sato C, eds. Design of Adhesive Joints under Humid Conditions. Heidelberg: Springer-Verlag Berlin; 2013:123-145.

19. Doyle G, Pethrick RA. Environmental effects on the ageing of epoxy adhesive joints. Int J Adhes Adhes. 2009;29(1):77-90. https://doi. org/10.1016/j.ijadhadh.2008.02.001

20. Loha WK, Crocombe AD, Abdel Wahab MM, Ashcroft IA. Environmental degradation of the interfacial fracture energy in an adhesively bonded joint. Eng Fract Mech. 2002;69(18):2113-2128. https://doi.org/10.1016/S0013-7944(02)00004-8

21. Arriaga M. Runway De-icing Material Effects on Aircraft Carbon Brakes. Presented to Airports Council International. Colorado: SAE International; 2008.

22. Myhra T. Deicing and Anti-icing Decisions for Runways and Ramps, Washington Airport Management Association (WAMA) Spring Conference. USA: Washington; 2015.

23. AITM 1-0053. AITM-Airbus Test Method-Carbon Fibre Reinforced Plastics-Determination of Fracture Toughness Energy of Bonded Joints-Mode I. France: Airbus S.A.S; 2006.
24. Davies P, Benzeggagh ML. Interlaminar mode-I fracture testing. In: Friedrich K, ed. Application of Fracture Mechanics to Composite Materials. Elsevier Science Publishers B.V; 1989:81-112.

25. Davis MJ, Bond DA. The importance of failure mode identification in adhesive bonded aircraft structures and repairs. Paper presented at: International Conference on Composite Materials 12 (ICCM-12), France, ICCM-12 Online Proceedings, 2012.

26. ASTM D5573-99. Standard Practice for Classifying Failure Modes in Fiber-Reinforced-Plastic (FRP) Joints. West Conshohocken, PA: ASTM International; 2005 www.astm.org.

27. de Moura MFSF, Campilho RDSG, Goncalves JPM. Pure mode II fracture characterization of composite bonded joints. Int J Solids Struct. 2009;46:1589-1595. https://doi.org/10.1016/j.ijsolstr.2008. 12.001

28. Carlsson LA, Gillespie JW Jr. Mode-II interlaminar fracture of composites. In: Friedrich K, ed. Application of Fracture Mechanics to Composite Materials. Elsevier Science Publishers B.V; 1989:113-122.

29. Pearson RA, Blackman BRK, Campilho RDSG, et al. Quasi-Static Fracture Tests. In: da Silva LFM, Dillard DA, Blackman B, Adams $\mathrm{RD}$, eds. Testing Adhesive Joints: Best Practices. Wiley-VCH Verlag \& Co. KGaA; 2012:163-191.

30. AITM 1-0006. AITM-Airbus Industry Test Method-Carbon Fibre Reinforced Plastics-Determination of Interlaminar Fracture Toughness Energy-Mode II. France: Airbus S.A.S; 1994.

31. DIN EN 2823 Aerospace series-fibre reinforced plastics-determination of the effect of exposure to humid atmosphere on physical and mechanical characteristics. European Association of Aerospace Industries (AECMA), German Institute for Characterization (DIN). Brussels, Belgium, 1998.

32. Floros IS, Tserpes KI, Lobel T. Mode-I, mode-II and mixed-mode I + II fracture behavior of composite bonded joints: experimental characterization and numerical simulation. Compos Part B Eng. 2015;78:459-468. https://doi.org/10.1016/j.compositesb.2015.04.006

33. Tornow C, Schlag M, Lima L, et al. Quality assurance concepts for adhesive bonding of composite aircraft structures-characterization of adherent surfaces by extended NDT. J Adhes Sci Technol. 2015;29(21):2281-2294. https://doi.org/10.1080/01694243.2015. 1055062

34. Crocombe AD, Ashcroft IA, Abdel Wahab MM. Environmental degradation. In: da Silva LFM, Öchsner A, eds. Modelling of Adhesively Bonded Joints. Heidelberg: Springer-Verlag Berlin; 2008:225-241

How to cite this article: Moutsompegka E, Tserpes KI, Polydoropoulou P, et al. Experimental study of the effect of pre-bond contamination with de-icing fluid and ageing on the fracture toughness of composite bonded joints. Fatigue Fract Eng Mater Struct. 2017;40:1581-1591. https://doi.org/10.1111/ ffe. 12660 